
PP Periodica Polytechnica
Architecture

RESEARCH ARTICLE
47(2), pp. 75-78, 2016

DOI: 10.3311/PPar.10087

Creative Commons Attribution (i)

\title{
Glass Box Method for Easy Solar Analysis Using Building Information Modelling
}

Riva Tomasowa ${ }^{1 *}$

Received 29 September 2016; accepted 17 October 2016

\begin{abstract}
Tropical sunlight contributes to raising a buildings internal temperature outside of the comfort zone. Simulating a sun study would give valuable information to determine a better design decision. However, the architect does not always interpret simulation results when deciding which orientation is best for their design. Possibly, a more user-friendly statistics chart of a simulation report is required. This simulation uses BIM to give an answer to such challenges. First, an equilateralbased model, which is articulated by an opening on every face, and satisfies BEM requirements, is constructed. Then the solar analysis is conducted in a tropical warm, humid site, Jakarta. As a result, the radiation from sunrise to noon carries the significant impact of radiation to the base model. By using a simple method, the solar analysis can easily be transformed into an orientation information. This approach enables an understanding of the solar radiation characteristics before starting the design stage.
\end{abstract}

\section{Keywords}

BIM, passive solar design, solar analysis

\footnotetext{
${ }^{1}$ Department of Architecture, Faculty of Engineering, Bina Nusantara University

Jalan K.H. Syahdan 9, Jakarta Barat 11480, Indonesia

*Corresponding author, e-mail: rivatomasowa@binus.ac.id
}

\section{Introduction}

$\mathrm{BIM}$ is popular for its rich information and its input to the pre-construction to the construction phase. However, BIM is not quite as conversant in helping the architect at the early project stage. Meanwhile, the architect needs information to construct the broader realm of the project in order to start on the proposal.

This paper presents a suggestion of how BIM could contribute in the pre-design phase as visual information, based on data analysis with a single BIM authoring tool and several open source applications. The goal of the research is to construct a simple method for solar analysis to fill the "hole" regarding the impact of environment variables in the early stages (Vannini and Turcienicz, 2015). The focus is on the intensity of solar radiation where the radiation is an inevitable issue in tropical regions. Research by Cheng et al. (2015) states that lighting quality and solar radiation data are the keys used for modifying the geometrical form to adapt the balance of solar heat gain and usable day lighting. It is has been shown that solar analysis has a meaningful influence on the architectural form finding process. However, this kind of challenge is solved by a sophisticated method that not every architect possesses. The architect still needs to evaluate the characteristics of their site in the first place.

Solar analysis has never been easier with the computer simulation compared to manual research. Nevertheless, it needs to be more architect friendly. The improvements in using 3D information should have an intuitive human-computer interaction (Morello et al., 2010), as not every architect is a scientist who can interpret numerical data. On the other hand, they are very fond of graphical information.

The proposed method is illustrated with a case study that assumes every architect is already familiar with BIM modelling using ArchiCAD as the authoring tool. Effortlessly means the learning curve is not steep, and as an existing user, there is zero cost. The aim of this discussion is a method to obtain solar analysis in the early stages. The next sections outline a case study in West Jakarta, Indonesia, both the procedure and the generation of the analysis. 


\section{A procedure for generating radiation data with the Glass Box method \\ 2.1 Data gathering}

On starting the project, ArchiCAD requires Project Information input, to identify the Project Location (Fig. 1b). A Google map, shown in Fig. 1a, is used to obtain the geolocation data, such as longitude and altitude. In addition, the altitude is obtained from Daft Logic (2013).

However, obtaining climate data is the most crucial and challenging. The Strusoft Climate Server seems to give inappropriate climate data for the Jakarta region. Therefore, another source is used, although, it had to be converted into a compatible format before loading it into the ArchiCAD Climate Data dialogue box (Fig. 1c). If the climate data works in the application, then the geolocation data is the important key to operate the simulation in the Building Energy Model (BEM) as shown in Fig. 1d.

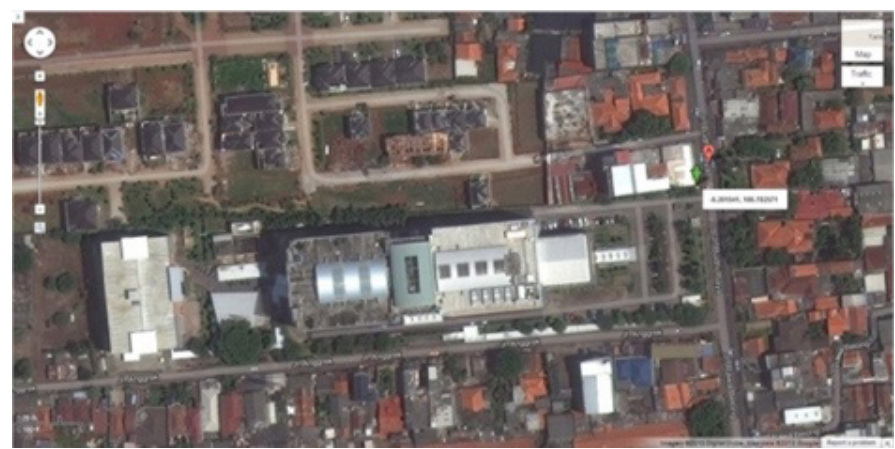

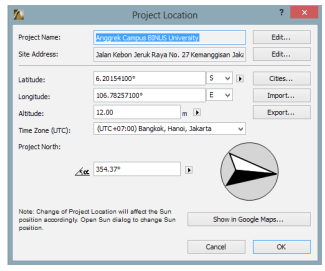

b)

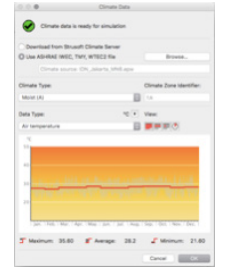

c)

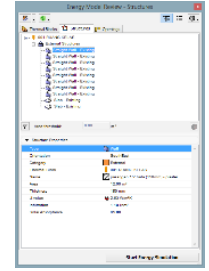

d)
Fig. 1 Geolocation data as inputs for BIM and BEM requirements.

\subsection{Modelling}

The Glass Box modelling workflow from BIM to (BEM) is explained in Fig. 2. The model is simply a one level zone with glazed wall enclosures. It is a very basic model according with the Graphisoft Reference Guide (Graphisoft SE, 2014). The minimum modelling elements consist of at least the floor, walls including windows, roof, and zone. In this modelling stage, the elements are not necessarily defined. The element details lie between LoD 100 and LoD 200 (BIM Forum, 2015). The important thing is that the windows are modelled to a full height and a full width to obtain maximum incident data on the surface, as the glazed area is the calculated object in EcoDesigner Solar Analysis.

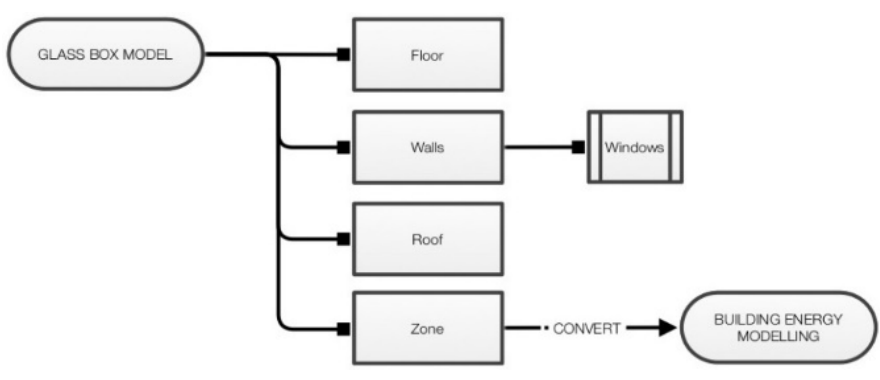

Fig. 2 Glass Box Method for Analysis.

There are at least two ways to produce a base model. First, is to model according to the building codes applied in the region. It is a site-indexed massing, a form-based code (Lévy, 2012). This approach gives a solid understanding of the possible orientations that might occur in the design development.

Secondly, if the site is still undefined, Fig. 3 shows that there are eight different equilateral footprint shapes recommended, such as triangle, rectangle, pentagon, hexagon, heptagon, octagon, nonagon, and decagon. The octagonal-based box used in this paper provides eight side-facing calculations, to eight compass orientations respectively. Each model should appear alone in a simulation scheme as they cannot stand side by side as one could overshadow another. This also means that existing buildings on the perimeter will contribute to the simulation results, and if needed, they are also developed at this stage.
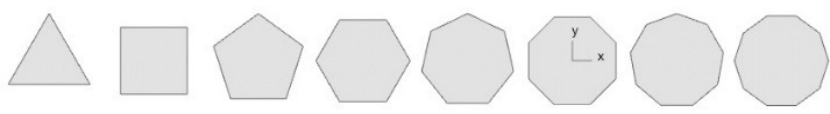

Fig. 3 Eight equilateral shapes used in the research.

\section{Generation of solar analysis data 3.1 Energy model review}

Aiming for a simple analysis, the recorded values are merely considered as a ratio for comparison purposes. I believe this is the nature of computer simulation. On Fig. 4, the eight results from each orientation show their annual direct radiation exposure value in a visual chart. The values of the annual integrated solar radiation for the octagon base model are:

- North: $9561.88 \mathrm{~kW} / \mathrm{h}$;

- North East: $9970.92 \mathrm{~kW} / \mathrm{h}$;

- East: $8858.71 \mathrm{~kW} / \mathrm{h}$;

- South East: $8051.63 \mathrm{~kW} / \mathrm{h}$;

- South: $6415.36 \mathrm{~kW} / \mathrm{h}$;

- South West: $5876.07 \mathrm{~kW} / \mathrm{h}$;

- West: $7024.9 \mathrm{~kW} / \mathrm{h}$; and

- North West: $7861.79 \mathrm{~kW} / \mathrm{h}$ 


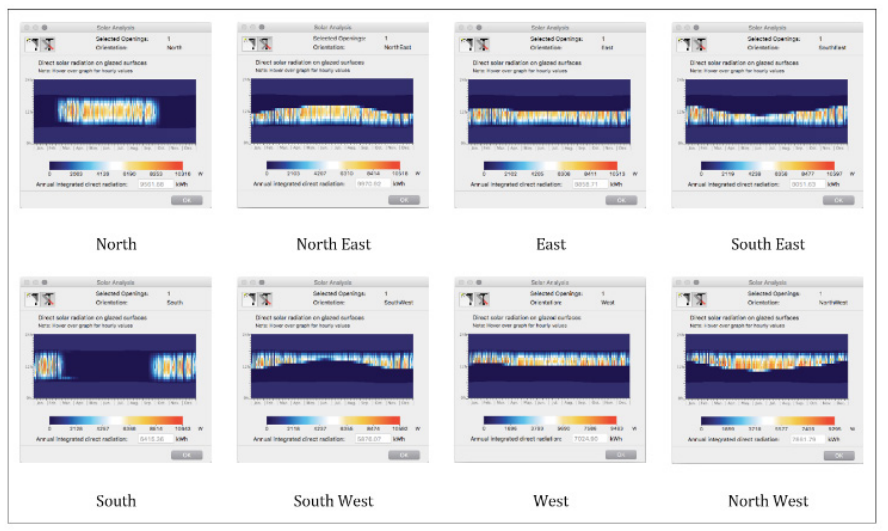

Fig. 4 Direct solar radiation on octagonal-shape box with glazed surface.

The data shows that the radiation is already affecting the windows from the morning, reaching the highest point somewhere around noon over the course of the year.

However, the visualisations represent the sun's path on the vertical planar glazed surfaces. These data are very useful for designing shading instead of giving information about orientation. Supposed the annual radiation values are compared between each of the simulated windows, they will then deliver much clearer information regarding orientation.

\subsection{The comparison}

ArchiCAD calculates solar radiation incidents in kilowatts per hour $(\mathrm{kW} / \mathrm{h})$, and it presents a 1-year span graphical interface. The comparison would be better if they were depicted in a radar chart as shown in Fig. 5. The chart immediately tells the viewer which orientation has the lowest or highest radiation over the year. Choosing the appropriate representation helps to clarify the information for a better understanding.

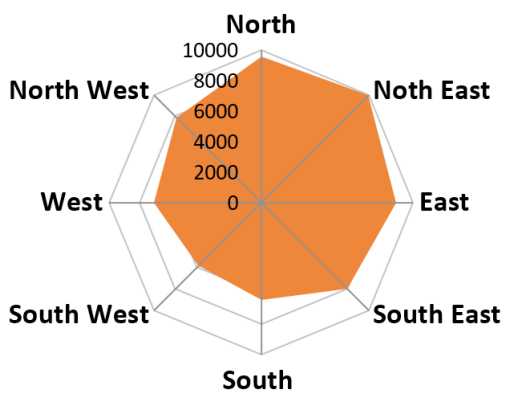

Fig. 5 Radar chart of annual integrated direct radiation for eight sides.

\section{Conclusion}

Figure 6 explains a detailed process, with the flowchart divided into three sections: modelling, energy model review, and creating a chart. By simulating eight different shapes as suggested in Fig. 3, the comparison between developed charts will give a better illustration. A number of sides can be conceived as the threshold in simulations. For those simple equilateral shape models, they could be saved as a template, which can be used for other projects. With this scheme, an easy simulation can be achieved in the early phase to reveal the solar characteristics of the area (site).

\section{Further Developments}

Nowadays, geolocation data can easily be obtained on a smartphone, through a compass app for instance. A small item of data is transformed into a significant one. In this case, geolocation is the key. The proposed glass box method could be developed as a predefined algorithm, either inside or outside

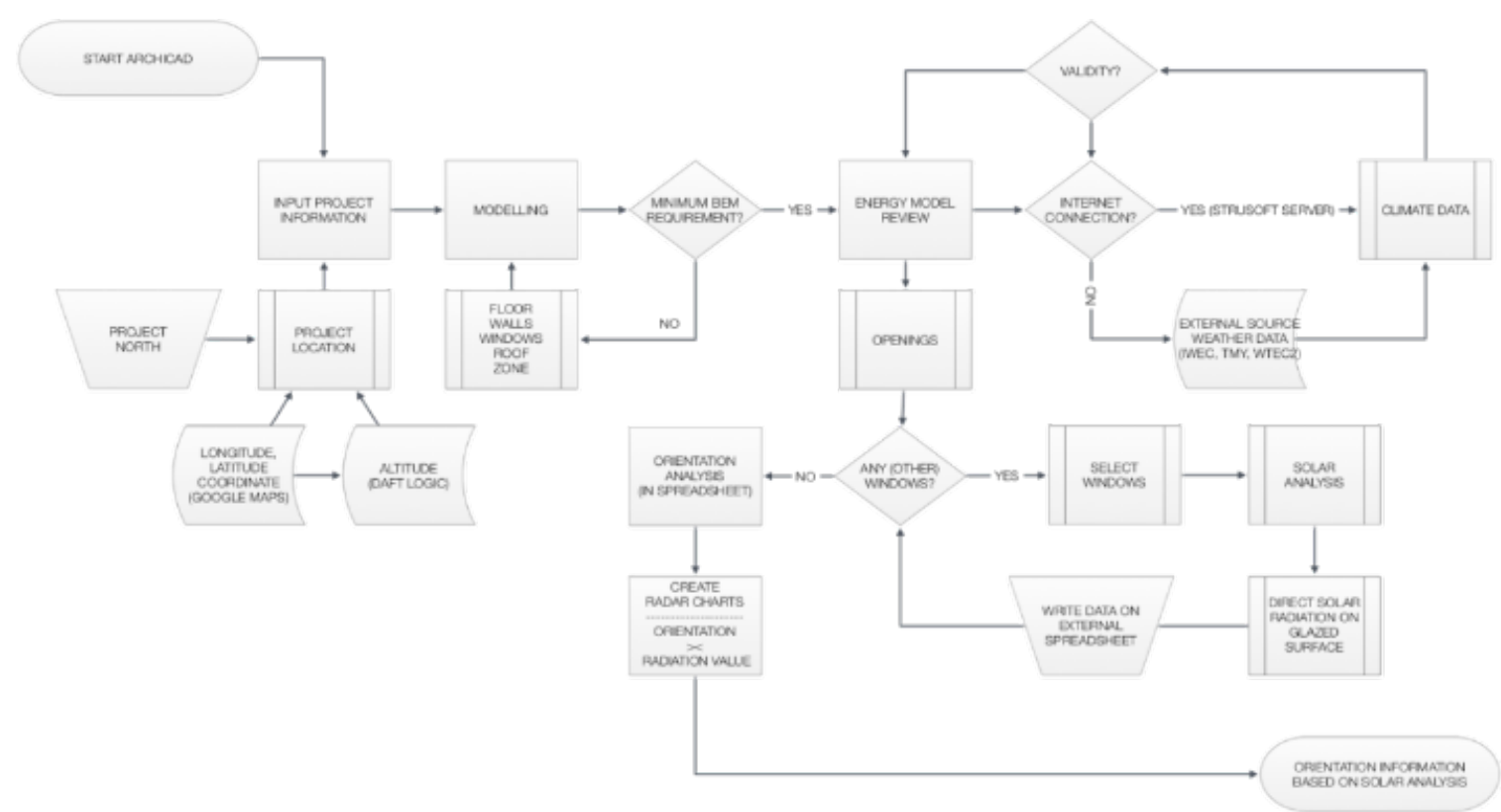

Fig. 6 Detailed systematic flowchart of the glass box method. 
ArchiCAD, like a mobile app. With the ubiquitous mobile technology, the predefined glass box simulation could be done in the cloud where the application supplies the data direct from the site. Figure 7 illustrates the information flow, starting from the project information input, and then retrieving the geolocation. After the simulation has been processed in the cloud server, the information is sent back to the app and represented in the form of a radar chart where the user can select a threshold that signifies their needs regarding the orientation.

For a better solution, the result should be shareable or could be imported back into BIM. The idea shown in Fig. 7 is one of the concepts that could be developed for making the solar analysis comprehensible.

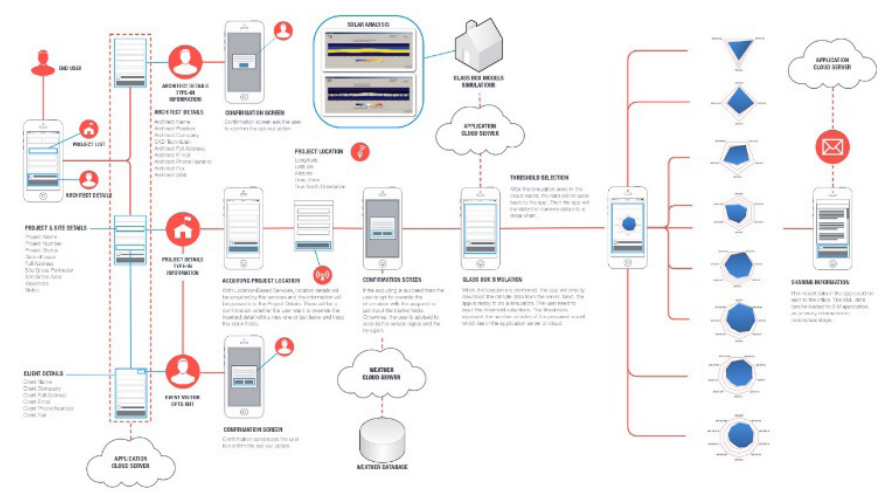

Fig. 7 Solar analysis in mobile app user experience concept.

\section{Acknowledgement}

This research was sponsored by a grant from Bina Nusantara University (005A/Dir.RIC/IV/2013).

\section{References}

BIM Forum. (2015) LOD | BIM Forum. [Online]. Available from: http://bimforum.org/wp-content/uploads/2015/11/Files-1.zip

Cheng, N. Y., Khorasgani, M. L., William, N., Prohasky, D., Burry, J. (2015) Understanding Light in Building Skin Design. Emerging Experience in Past, Present and Future of Digital Architecture. In: Proceedings of the 20th International Conference of the Association for Computer-Aided Architectural Design Research in Asia (CAADRIA 2015), pp. 323-332.

Daft Logic. (2013) Google Maps Find Altitude. [Online]. Available from: https://www.daftlogic.com/sandbox-google-maps-find-altitude.htm

Graphisoft SE. (2014) Prepare the Architectural BIM for Energy Evaluation. [Online]. Available from: http://helpcenter.graphisoft.com/guides/archicad-18/archicad-18-int-reference-guide/energy-evaluation/energy-evaluation-workflow-overview/prepare-the-architectural-bim-for-energyevaluation/

Lévy, F. (2012) BIM in Small-Scale Sustainable Design. John Wiley \& Sons.

Morello, E., Carneiro, C., Desthieux, G. (2010) The Use of Digital 3-D Information to Assess Urban Environmental Quality Indicators. In: FUTURE CITIES. 28th eCAADe Conference Proceedings, Sept. 15-18, 2010, pp. 499-506

Vannini, V. C., Turcienicz, B. (2015) Thermal Performance Associated with Materials in Early Stages of the Design Process. In: Real Time - Proceedings of the 33rd eCAADe Conference, Vol.1, 2015, pp. 325-331. 